\title{
Concentrações séricas de aspartato aminotransferase e creatinoquinase e concentrações plasmáticas de lactato em equinos da raça Mangalarga Marchador após exercício físico
}

\section{Serum aspartate aminotransferase and creatine kinase concentrations and plasma lactate in Mangalarga Marchador horses after physical exercise}

\author{
Juliana Almeida Nogueira da GAMA ${ }^{1}$; Meryelli Sales de SOUZA²; Evandro PEREIRA NETO³; Vinicius \\ Ricardo Cuña de SOUZA ${ }^{4}$; Clarisse Simões COELHO ${ }^{5}$

\begin{abstract}
${ }^{1}$ Mestranda do Programa de Pós-Graduação em Medicina Veterinária da Universidade Estadual Paulista, Botucatu-SP, Brasil
${ }^{2}$ Aluno de graduação da Faculdade de Medicina Veterinária e Zootecnia da Universidade Vila Velha, Vila Velha-ES, Brasil ${ }^{3}$ Mestrando do Programa de Mestrado em Ciência Animal da Universidade Vila Velha, Vila Velha-ES, Brasil

${ }^{4}$ Professor do Curso de Graduação em Medicina Veterinária e do Programa de Mestrado em Ciência Animal da Universidade Vila Velha, Vila Velha-ES, Brasil

${ }^{5}$ Professor do Curso de Graduação em Medicina Veterinária e do Programa de Mestrado em Ciência Animal da Universidade
\end{abstract} \\ Vila Velha, Vila Velha-ES, Brasil
}

\begin{abstract}
Resumo
O objetivo do trabalho foi avaliar a influência do exercício físico (provas de marcha) sobre os valores séricos de AST e CK e valores plasmáticos de lactato em equinos da raça Mangalarga Marchador criados no estado do Espírito Santo. Amostras de soro e plasma foram obtidas de 15 equinos em quarto diferentes momentos: repouso (T0) e com 5 minutos (T1), 30 minutos (T2) e 2 horas (T3) após o término do exercício. Foram registrados valores de lactato plasmático de $1,02 \pm 0,41 \mathrm{mmol} / \mathrm{L}, 2,73 \pm 2,43 \mathrm{mmol} / \mathrm{L}, 1,89 \pm 1,24 \mathrm{mmol} / \mathrm{L}$ e $1,31 \pm 0,60 \mathrm{mmol} / \mathrm{L}$, respectivamente nos momentos T0, T1, T2 e T3. Na análise de AST, os resultados registrados nos momentos T0, T1, T2 e T3 foram, respectivamente, de $189,3 \pm 56,0 \mathrm{UI} / \mathrm{L}, 223,9 \pm 53,5 \mathrm{UI} / \mathrm{L}, 186,8 \pm 25,8 \mathrm{UI} / \mathrm{L}$ e $193,9 \pm 44,7 \mathrm{UI} / \mathrm{L}$. Finalmente, os valores séricos de CK foram de 113,4 \pm 56,3 UI/1, 144.1 \pm 70,9 UI/L, 143,0 \pm 81,0 UI/L e 173,1 $\pm 128,0 \mathrm{UI} / \mathrm{L}$, respectivamente nos momentos T0, T1, T2 and T3. A análise dos resultados demonstrou que a marcha influenciou de forma significativa o lactato plasmático, porém não influenciou a atividade sérica de AST e CK, sugerindo que os equinos usados encontravam-se condicionados ao exercício físico imposto.
\end{abstract}

Palavras-chave: Equinos. AST. CK. Lactato. Provas de marcha. Exercício.

\begin{abstract}
The aim of this study was evaluate the influence of physical exercise (marcha gait) on serum values of CK and AST and plasmatic values of lactate in Mangalarga Marchador horses trained in Espirito Santo, Brazil. Serum and plasma samples were obtained from 15 horses in four different moments: rest (T0), 5 minutes (T1), 30 minutes (T2) and 2 hours (T3) after the exercise. Lactate analysis revealed values of $1.02 \pm 0.41 \mathrm{mmol} / \mathrm{L}, 2.73 \pm 2.43 \mathrm{mmol} / \mathrm{L}, 1.89 \pm 1.24 \mathrm{mmol} / \mathrm{L}$ and $1.31 \pm 0.60 \mathrm{mmol} / \mathrm{L}$, respectively at T0, T1, T2 and T3. When evaluating AST, the results recorded in T0, T1, T2 and T3 were, respectively, 189.3 $\pm 56.0 \mathrm{UI} / \mathrm{L}, 223.9 \pm 53.5 \mathrm{UI} / \mathrm{L}, 186.8 \pm 25.8 \mathrm{UI} / \mathrm{L}$ and $193.9 \pm 44.7 \mathrm{UI} / \mathrm{L}$. Finally, the CK at moments T0, T1, T2 and T3 were, respectively, $113.4 \pm 56.3 \mathrm{UI} / 1,144.1 \pm 70.9 \mathrm{UI} / \mathrm{L}, 143.0 \pm 81.0 \mathrm{UI} / \mathrm{L}$ and $173.1 \pm 128.0$ UI/L. The results showed that marcha gait leaded to significantly increased in plasma lactate and did not alter serum AST and CK, suggesting that the equines used were conditioned to the physical exercised imposed.
\end{abstract}

Keywords: Horses. AST. CK. Lactate. Marcha gait. Exercise.

\section{Introdução}

A raça Mangalarga Marchador (ou "Mangalarga Mineiro") é a mais numerosa do país. Tipicamente brasileira, surgiu há cerca de 200 anos no sul de Minas Gerais, através do cruzamento de cavalos da raça Alter (Coudelaria de Alter do Chão - Portugal) com outros cavalos selecionados pelos criadores daquela
Correspondência para:

Clarisse Simões Coelho

Professor do Curso de Graduação em Medicina Veterinária e do Programa

de Mestrado em Ciência Animal

Universidade Vila Velha (UVV)

Rua Comissário José Dantas de Melo, 21, Vila Velha - ES

CEP: 29102-770

e-mail: clarisse.coelho@uvv.br

Recebido: 16/02/12

Aprovado: 20/12/12 
região mineira ${ }^{1}$. Poucas pesquisas são realizadas com esta raça, cujo andamento característico é a marcha, um teste exaustivo sem similar em todo o mundo, no qual o animal realiza um exercício de longa duração, com grande gasto energético, num percurso em círculo, sem repouso e em velocidade constante ${ }^{2}$.

É sabido que o exercício físico realizado durante treinamentos ou competições gera em humanos e animais variações em diversos parâmetros fisiológicos ${ }^{3} \mathrm{e}$ a compreensão de tais mecanismos fisiológicos e sua caracterização são de enorme importância na avaliação da performance destes animais ${ }^{4}$.

A aspartato aminotransferase (AST) é uma enzima citoplasmática e mitocondrial presente em diversos tecidos, principalmente, fígado e músculos esquelético e cardíaco. Portanto, é bastante usada no diagnóstico de afecções acometendo estes órgãos. Já a creatinoquinase (CK) é uma enzima de alta especificidade para lesões musculares, encontrada principalmente no citosol das células musculares (músculos esquelético e cardíaco $)^{5}$.

Robinson ${ }^{6}$ cita valores para AST de 141-330 UI/L e para CK de 2-147 UI/L para equinos da raça Puro Sangue Inglês. Também em equinos da raça PSI, no repouso, os valores médios para a atividade de AST obtidos por Valberg ${ }^{5}$ foram de $296,0 \pm 70,0$ UI/L e de $12,9 \pm 5,2$ UI/L para a atividade enzimática de CK. Franciscato et al. ${ }^{7}$ citaram valores médios de 209,67 UI/L para AST e de 159,81 UI/L para CK em equinos da raça Crioula em treinamento. Trabalho mais recente de Pritchard et al. ${ }^{8}$ citou valores de AST sérico de 189-456 UI/L e valores de 123-358 UI/L para CK sérico.

Geralmente, a determinação sérica das atividades da AST, CK e lactato desidrogenase (LDH) é usada na avaliação dos efeitos do exercício físico sobre a musculatura $^{8,9}$. Segundo Valberg ${ }^{10}$, a permeabilidade do sarcolema aumenta durante o exercício e as enzimas podem escoar para o plasma, porém os resultados descritos na literatura são controversos, com alguns autores citando influência positiva (ou seja, aumento dos valores sanguíneos das referidas variáveis) ou a não interferência do exercício sobre estes constituintes sanguíneos ${ }^{11,12,13,14,15}$. Câmara e Silva, Dias e Soto-Blanco ${ }^{9}$ ressaltam que as concentrações de AST e CK poderiam ser influenciadas pela fase de treinamento e pelo tipo de exercício e Harris, Marlin e Gray ${ }^{16}$ citam que, se a duração do exercício for mantida constante, a intensidade do mesmo, ou seja, a velocidade imposta, determina o aumento de suas concentrações séricas.

Outro ponto importante a ser avaliado é a adequada produção e utilização de energia pela musculatura, fatores essenciais para o ótimo desempenho do equino atleta ${ }^{17}$. Os valores basais de lactato plasmático, produto final da glicólise anaeróbica, oscilam no repouso entre 0,5-1,0 $\mathrm{mmol} / \mathrm{L}$ em cavalos de corrida e, após corrida ou esforço intenso, as concentrações séricas podem atingir até $25-30 \mathrm{mmol} / \mathrm{L}^{18}$. De uma forma geral, o aumento da concentração de lactato plasmático poderá ser usado para indicar a capacidade atlética do cavalo visto que animais que apresentam grande capacidade aeróbia geralmente têm baixas elevações das concentrações de lactato em resposta ao exercício ou apresentam uma clearance mais eficiente ${ }^{5}$. Acima de $30 \mathrm{mmol} / \mathrm{L}$ ocorre declínio do $\mathrm{pH}$ sanguíneo, em consequência da falha no clearance do lactato acumulado, levando a acidemia, fadiga muscular e a miopatia $^{19}$. Associa-se a tal fato, uma musculatura não adaptada à intensidade de exercício imposto.

Existem diversos estudos na literatura ${ }^{4,7,8,14,17,20}$ avaliando a performance de cavalos de corrida e de enduro, sendo poucos os relatos envolvendo equinos da raça Mangalarga Marchador, treinados em condições climáticas tropicais, como as encontradas no Brasil. O objetivo do presente trabalho foi avaliar a influência do exercício físico intenso (provas de marcha) sobre as variáveis bioquímicas sanguíneas rotineiramente usadas na avaliação do metabolismo muscular (AST e CK séricos e lactato plasmático) em equinos da raça Mangalarga Marchador criados no Estado do Espírito Santo. 


\section{Material e Método}

Foram utilizados 15 equinos da raça Mangalarga Marchador, sendo nove fêmeas e seis machos, pesando em média $399 \pm 34 \mathrm{~kg}$, com idade variando entre três e dez anos (média de 4,6 $\pm 1,9$ anos de idade), considerados clinicamente hígidos, mediante exames clínico (exame físico) e laboratorial (hemograma). Estes animais pertencem a dois haras de criadores de equinos Mangalarga Marchador, localizados na região de Vitória - ES, Brasil. A temperatura média local foi de $24^{\circ} \mathrm{C}$ e umidade relativa do ar de $80 \%$. Todos os animais são submetidos ao mesmo tipo de manejo alimentar e sanitário.

A alimentação dos animais foi baseada nos relatos de Ralston ${ }^{21}$, sendo fornecido feno de coast-cross ( $C y$ nodon dactylon x Cynodon nlemfluensis) ad libitum e ração comercial (DoEqui TopQuality), com $12 \%$ de proteína bruta, a $1 \%$ do peso corporal, divididos em três vezes ao dia. A água e sal mineral foram fornecidos ad libitum.

Todos os equinos selecionados encontravam-se no mesmo estágio de treinamento, ou seja, encontravam-se na mesma categoria segundo a Associação Brasileira dos Criadores do Cavalo Mangalarga Marchador (ABCCMM) e executavam tal atividade há pelo menos dois anos. O treinamento semanal consistia de exercício com o animal a passo por um período de 25 a 30 minutos até 2 a 3 horas, duas vezes na semana, alternando nos demais três dias com exercícios montados, em marcha, por 30 a 40 minutos. Aos finais de semana os animais descansavam.

$\mathrm{Na}$ presente pesquisa, os animais executaram marcha cadenciada, sendo 20 minutos em sentido horário e 20 minutos em sentido anti-horário, em velocidade média de 9 a $12 \mathrm{~km} / \mathrm{h}$, totalizando 40 minutos, mimetizando uma prova executada pela ABCCMM.

Foram quatro momentos de avaliação de cada um dos animais, sendo assim caracterizadas: antes - T0 (obtida antes da prova atlética, com o animal em re- pouso), pós-treino 1 - T1 (obtida num período máximo de cinco minutos após a realização da atividade física), pós-treino 2 - T2 (obtida 30 minutos após a realização da atividade física) e pós-treino 3 - T3 (obtida 2 horas após a realização da atividade física). Todas as atividades foram realizadas no período da manhã (entre 6h:00 e 11h:00), quando também foram registradas as características da pista.

As amostras de sangue foram obtidas, após antissepsia local, por meio de venopunção da jugular com agulhas descartáveis ( $25 \mathrm{~mm} \times 0,8 \mathrm{~mm}$ ), utilizando-se sistema a pressão negativa (Vacutainer ${ }^{\circledR}$ ), em tubos de vidro contendo anticoagulante EDTA-fluoreto de sódio com capacidade de $2 \mathrm{~mL}$, para avaliação plasmática de lactato, e em tubos de vidro siliconizados sem anticoagulante com capacidade de $9 \mathrm{~mL}$, para as determinações séricas de AST e CK. Todas as 60 amostras foram transportadas sob refrigeração ao Laboratório Clínico Veterinário do Centro Universitário Vila Velha (UVV), onde foram imediatamente centrifugadas (3500 rpm) durante 10 minutos (Centrífuga modelo TDL80-2B, Marca Centribio) para separação de soro/plasma.

A determinação de lactato plasmático foi realizada através de metodologia enzimática, como indicado pelo kit comercial (Katal - LOD-PAP), segundo metodologia de $\mathrm{Pryce}^{22}$, em analisador bioquímico semiautomático (Bioplus - BIO200). No soro, a atividade da enzima AST foi determinada através de kit comercial (Bioclin - K048) em analisador bioquímico semiautomático (Bioplus - BIO 200), em comprimento de onda de $340 \mathrm{~nm}^{23}$. Também no soro, a atividade $\mathrm{CK}$ foi quantificada em analisador bioquímico semiautomático (Bioplus - BIO200), em comprimento de onda de $340 \mathrm{~nm}$, utilizando-se kit comercial (Bioclin - K010) ${ }^{24}$.

A análise dos resultados foi realizada utilizando-se o programa estatístico computadorizado GraphPad InStat (versão 3.0). Os dados foram avaliados através de testes paramétricos (análise de variância - ANO- 
VA) seguido da comparação entre médias (teste de Tukey) com nível de significância de 5\%. Nestas análises, levou-se em consideração a influência do exercício físico sobre as concentrações das variáveis estudadas (análise de variância one-way).

\section{Resultados e Discussão}

Nos exames clínicos realizados para seleção dos equinos usados na presente pesquisa, os valores médios registrados foram: frequência cardíaca de 45 bpm, frequência respiratória de $20 \mathrm{mpm}$, motilidade intestinal presente à auscultação, mucosas róseas e temperatura retal de $37,5^{\circ} \mathrm{C}$. Na avaliação do hemograma, os valores médios encontrados foram de $7,25 \times 10^{6} / \mu \mathrm{L}$ para número de eritrócitos, $11,99 \mathrm{~g} / \mathrm{dL}$ para concentração de hemoglobina, 35\% para volume globular, 49,01 fl para VCM (volume corpuscular médio), 33,79 g/dL para CHCM (concentração de hemoglobina corpuscular média) e 9533 leucócitos/ $\mu \mathrm{L}$. Tais valores encontram-se dentro da normalidade segundo Robinson ${ }^{6}$.

Os equinos usados foram exercitados em três dias. As características do clima local são típicas de regiões tropicais, com altas temperaturas e alta umidade. A pista de grama encontrava-se seca.

$\mathrm{Na}$ tabela 1 estão apresentados os valores médios e desvios-padrão para os valores séricos de AST e CK e valores plasmáticos de lactato, além dos valores de $p$ obtidos na análise de variância (ANOVA).

$\mathrm{Na}$ avaliação de AST é possível observar que não houve diferença significativa nos diferentes momentos de avaliação, apesar da tendência à elevação entre T0 e T1. Todos os valores registrados encontram-se dentro dos limites fisiológicos citados por Robinson ${ }^{6}$ e Pritchard et al..$^{8}$ e similares ao registrado em trabalho nacional por Franciscato et al. .

Os resultados da presente pesquisa, em relação às atividades séricas de AST, mostraram-se semelhante aos descritos por Balarin et al. ${ }^{13}$, Kowal et al. ${ }^{14}$ e Mar- tins et al..$^{20}$ e que descreveram que os valores séricos desta enzima não apresentaram alterações significativas nas diferentes intensidades de exercício estudadas (trote, galope e enduro, respectivamente). Entretanto, foram diferentes de autores como Câmara e Silva, Dias e Soto-Blanco ${ }^{9}$, Valberg ${ }^{10}$ e Tateo et al. ${ }^{25}$ que registraram aumento nas concentrações séricas da referida enzima em consequência do aumento da permeabilidade do sarcolema gerada pela atividade física. Câmara e Silva, Dias e Soto-Blanco ${ }^{9}$ ainda justificaram que tal aumento seria influenciado pela fase do treinamento e tipo de exercício. Portanto, equinos treinados e condicionados à atividade física imposta teriam uma menor magnitude de aumento na AST sérica.

O pico de AST após uma atividade física ocorre com 24 horas após o término deste, segundo Thomas$\operatorname{sian}^{26}$. Por este fato, uma amostra extra de cada equino foi obtida após 24 horas da finalização do exercício exclusivamente para verificar se houve aumento da atividade enzimática em consequência do exercício e o valor médio registrado foi de $192,7 \pm 58,6 \mathrm{UI} / \mathrm{L}$, apresentando-se sem diferenças significativas em relação aos demais momentos.

Semelhante ao registrado para AST, a avaliação de CK também demonstrou não haver diferença significativa entre os momentos de avaliação, com os valores registrados também se encaixando dentro dos limites fisiológicos citados por Robinson ${ }^{6} \mathrm{e}$ Pritchard et al. ${ }^{8}$. Este achado difere das citações de Valberg ${ }^{5}$, Balarin et al. ${ }^{13}$ e Kowal et al. ${ }^{14}$, que, conforme supracitado para AST, justificam o aumento de CK no pós-exercício pelo aumento da permeabilidade do sarcolema, com influência também do tipo de exercício e treinamento 9 . Porém, os achados da presente pesquisa podem sugerir que os equinos usados estavam condicionados ao nível de atividade física imposta, conforme também descreveram Franciscato et al. ${ }^{7}$ e Câmara e Silva, Dias e Soto- 
Tabela 1 - Valores médios e desvios-padrão da concentração de lactato plasmático e de AST e CK séricos nos equinos da raça Mangalarga Marchador, em uma sessão de exercício físico, nos momentos T0, T1, T2 e T3

\begin{tabular}{lccccc}
\hline & T0 & T1 & T2 & T3 & $p$ \\
\hline $\begin{array}{l}\text { Lactato } \\
(\mathrm{mmol} / \mathrm{L})\end{array}$ & $1,02 \pm 0,41^{\mathrm{a}^{*}}$ & $2,73 \pm 2,43^{\mathrm{b}}$ & $1,89 \pm 1,24^{\mathrm{ab}}$ & $1,31 \pm 0,60^{\mathrm{a}}$ & 0,0117 \\
AST (UI/L) & $189,3 \pm 56,0^{\mathrm{a}^{*}}$ & $223,9 \pm 53,5^{\mathrm{a}}$ & $186,8 \pm 25,8^{\mathrm{a}}$ & $193,9 \pm 44,7^{\mathrm{a}}$ & 0,1187 \\
$\mathrm{CK}(\mathrm{UI} / \mathrm{L})$ & $113,4 \pm 56,3^{\mathrm{a}}$ & $144,1 \pm 70,9^{\mathrm{a}}$ & $143,0 \pm 81,0^{\mathrm{a}}$ & $173,1 \pm 128,0^{\mathrm{a}}$ & 0,3522 \\
\hline
\end{tabular}

* Letras minúsculas diferentes na mesma linha denotam diferença estatística significativa entre as médias $(\mathrm{p}<0,05)$ obtido pelo teste ANOVA. T0 (obtida antes da atividade física), T1 (obtida num período de até no máximo cinco minutos após o término da atividade física), T2 (obtida 30 minutos após o término da atividade física) e T3 (obtida 2 horas após o término da atividade física)

-Blanco9 ${ }^{9}$, visto que aumentos de menor magnitude ou a não interferência nos valores de CK pós-atividade física estariam correlacionadas com treinamento adequado ajustado ao condicionamento físico dos animais.

As diferenças observadas com relação aos valores obtidos por outros autores, tanto para AST quanto para CK, são decorrentes das diferenças nas raças estudadas e dos fatores ambientais e de manejo e reforçam a importância do estabelecimento de valores regionais para as referidas variáveis sanguíneas, de forma a tornar tais exames laboratoriais valiosos na avaliação da atividade física dos equinos.

Os valores médios registrados no repouso $(1,02$ $\pm 0,41 \mathrm{mmol} / \mathrm{L}$ ) para lactato plasmático foram semelhantes aos descritos por McGowan ${ }^{18}$ em cavalos de corrida. É possível observar que houve aumento significativo nos níveis plasmáticos de lactato imediatamente após a realização do exercício físico, quando os valores oscilaram entre 0,55 e 5,10 $\mathrm{mmol} / \mathrm{L}$, com valor médio de 2,73 $\pm 2,43 \mathrm{mmol} / \mathrm{L}$. A elevação nas concentrações de lactato plasmáticas pós-atividade física é esperada e permite determinar o sistema com maior contribuição à produção de energia, além de indicar a capacidade atlética do animal ${ }^{27}$. O exercício de alta intensidade e curta duração promove aumento de lactato plasmático superior a $4 \mathrm{mmol} / \mathrm{L}$, com a maior contribuição na produção de energia sendo via anaeróbica, e os exercícios de intensidade moderada (submáxima) e longa duração caracterizam aumentos plasmáticos entre 2,5 e $4 \mathrm{mmol} / \mathrm{L}$, com predominância do metabolismo aeróbico ${ }^{28,29}$. A partir desta análise, é possível dizer que a marcha desenvolvida pelos equinos da presente pesquisa representou um exercício de longa duração e intensidade moderada, visto que os valores médios pós-treino foram inferiores a 4 $\mathrm{mmol} / \mathrm{L}$.

Equinos em bom condicionamento atlético apresentam melhor taxa de remoção do lactato produzido pelo músculo, melhorando sua capacidade tamponante citoplasmática ${ }^{30}$. Assim, o tempo de retorno aos valores basais seria também um índice da capacidade de recuperação do animal. A normalização dos valores plasmáticos de lactato ocorreu no momento T3, ou seja, duas horas após o término do exercício, fato considerado bom por se tratar de um exercício de longa duração.

Vale ressaltar a necessidade de correlacionar os valores de lactato plasmático com os sinais clínicos. Todos os animais usados não demonstraram quaisquer alterações clínicas. Animais mal condicionados podem demonstrar fadiga muscular após exercício físico, atingindo valores de lactato plasmático relativamente baixos, demonstrando a incapacidade de produção de energia para aquele nível de atividade. Este fato foi comprovado por Mirian $^{31}$ que demonstrou valores de $8,57 \mathrm{mmol} / \mathrm{L}$ nos cavalos de 
Hipismo Clássico bem condicionados que completaram o percurso, e de somente $4,97 \mathrm{mmol} / \mathrm{L}$, nos animais mal condicionados.

\section{Conclusão}

Os resultados da presente pesquisa permitem concluir que o exercício físico imposto através da prova de marcha não influenciou os valores séricos de AST e CK, porém gerou um aumento significativo nos valores plasmáticos de lactato. O nível de elevação ob-

\section{Referências}

1. ASSOCIAÇÃO BRASILEIRA DOS CRIADORES DE CAVALOS MANGALARGA MARCHADOR - ABCCMM. Provas Técnicas. Disponível em: http://www.abccmm.org.br Acesso em: 09 fev. 2011

2. REZENDE, A. S. C. Aditivos ou suplementos? Mangalarga Marchador. Revista Oficial da ABCCMM, v. 18, n. 59, p. 4448, 2006.

3. KIENZLE. E.; FREISMUTH A.; REUSCH, A. Double blind placebo controlled vitamin $\mathrm{E}$ ou selenium supplementation of Sport horses with unspecified muscle problems. Journal of Nutrition, v. 136, n. 7, p. 2045-2047, 2006.

4. MARQUES, M. S.; FERNANDES, W. R.; COELHO, C. S.; MIRANDOLA, R. M. S. Influência do exercício físico sobre os níveis de lactato plasmático e cortisol sérico em cavalos de corrida. A Hora Veterinária, v. 22, n. 129, p. 29-32, 2002.

5. VALBERG, S. J. Skeletal muscle function, In: KANEKO, J. J.; HARVEY, J. W.; BRUSS, M. L. (Eds), Clinical Biochemistry of Domestic Animals. 6. ed. London: Academic Press, 2008. p. 459-484.

6. ROBINSON, E. N. Current therapy in equine medicine. 5. ed. Philadelphia: Saunders, 2003. 960 p.

7. FRANCISCATO, C.; LOPES, S. T. A.; VEIGA, A. P. M.; MARTINS, D. B.; EMANUELLI, M. P.; OLIVEIRA, L. S S. Atividade sérica das enzimas AST, CK e GGT em cavalos Crioulos. Pesquisa Agropecuária Brasileira, v. 41, n. 10, p. 1561-1565, 2006.

8. PRITCHARD, J. C.; BURN, C. C.; BARR, A. R. S.; WHAY, H. R. Haematological and serum biochemical reference values for apparently healthy working horses in Pakistan. Research in Veterinary Science, v. 87, p. 389-395, 2009.

9. CÂMARA E SILVA, I. A.; DIAS, R. V. C.; SOTO-BLANCO B. Determinação das atividades séricas de creatina quinase, lactato desidrogenase e aspartato aminotransferase em equinos de diferentes categorias de atividade. Arquivo Brasileiro de Medicina Veterinária e Zootecnia, v. 59, n. 1, p. 250-252, 2007.

10.VALBERG, S. J. Muscular causes of exercise intolerance in horses. Veterinary Clinics of North America: Equine Practice, v. 12, p. 495-515, 1996.

11.ROSE, J. R.; ARNOLD, K. S.; CHURCH, S. Plasma and sweat electrolyte concentrations in the horse during long distance exercise. Equine Veterinary Journal, v. 12, n. 1, p. 19-22, 1980. servado para tal variável confirma que a obtenção de energia para execução do mesmo foi feita principalmente pela glicólise aeróbica.

Foi também possível concluir que os equinos usados na referida sessão de atividade física encontravam-se fisicamente condicionados ao tipo de exercício imposto, visto que os valores registrados estavam dentro de limites fisiológicos pós-exercício para o tipo de exercício imposto e os animais não demonstraram sinais clínicos de fadiga.

12.FREESTONE, J. F.; WOLFSHEIMER, K. J.; KAMERLING, S. G.; CHURCH, G.; HAMRA, J.; BAGWELL, C. Exercise induced hormonal and metabolic changes in Thoroughbred horses: effects of conditioning and acepromazine. Equine Veterinary Journal, v. 23, n. 3, p. 219-223, 1991.

13. BALARIN, M. R. S.; LOPES, R. S.; KOHAYAGAWA, A.; LAPOSY, C. B.; FONTEQUE, J. R. Avaliação da glicemia e da atividade sérica de aspartato aminotransferase, creatinoquinase, gama- glutamiltransferase e lactato desidrogenase em equinos puro sangue inglês (PSI) submetidos a exercícios de diferentes intensidades. Semina: Ciências Agrárias, v. 26, n. 2, p. 211 218,2005

14.KOWAL, R. J.; ALMOSNY, N. R. P.; CASCARDO, B.; SUMMA, R. P.; CURY, L. J. Avaliação dos valores de lactato e da atividade sérica da enzima creatina quinase (2.7.3.2) em cavalos (Equus caballus) da raça Puro-Sangue-Inglês (PSI) submetidos a teste de esforço em esteira ergométrica. Revista Brasileira de Ciência Veterinária, v. 13, n. 1, p. 13-19, 2006.

15.PADALINO, B.; RUBINO, G.; CENTODUCATI, P.; PETAZZI, F. Training versus overtraining: evaluation of two protocols. Journal of Equine Veterinary Science, v. 27, n. 1, p. 28-31, 2007.

16.HARRIS, P. A.; MARLIN, D. J.; GRAY, J. Plasma aspartate aminotransferase and creatine kinase activities in thoroughbred racehorses in relation to age, sex, exercice and training. Veterinary Journal, v. 155, p. 295-304, 1998.

17.GOMIDE, L. M. W.; MARTINS, C. B.; OROZCO, C. A. G.; SAMPAIO, R. C. L.; BELLI, T.; BALDISSERA, V.; LACERDA NETO, J. C. Concentrações sanguíneas de lactato em equinos durante a prova de fundo do concurso completo de equitação. Ciencia Rural, v. 36, n. 2, p. 509-513, 2006.

18. McGOWAN, C. Clinical pathology in the racing horse: the role of clinical pathology in assessing fitness and performance in the racehorse. The Veterinary Clinics of North America: Equine Practice, v. 24, n. 2, p. 405-421, 2008.

19.PÖSÖ, A. R. Monocarboxylate transporters and lactate metabolism in equine athletes: a review. Acta Veterinaria Scandinavica, v. 43, n. 2, p. 63-74, 2002.

20.MARTINS, C. B.; OROZCO, C. A. G.; D'ANGELIS, F. H. F.; FREITAS, E. V. V.; CHRISTOVÃO, F. G.; QUEIROZ NETO, A.; LACERDA NETO, J. C. Determinação de variáveis bioquímicas em equinos antes e apos a participação em provas de enduro. Revista Brasileira de Ciência Veterinária, v. 12, n. $1 / 3$, p. $62-65,2005$. 
21. RALSTON, S. L. Equine Clinical Nutrition: Specific problems and solutions. Compendium on Continuing Education, v. 10, n. 3, p. 356-363, 1988.

22.PRYCE, J. D. A modification of Barker-Summerson method for the determination of lactic acid. Analyst, v. 94, p. 11511152,1969

23. BERGMEYER, H. U. Methods of enzymatic analysis. EUA: Academic Press, 1974. 1064 p.

24.SCHMID, M.; FOSTNER, L. A. Laboratorie testing in veterinary medicine diagnosis in the clinical monitoring. Mannheim: Boehringer, 1986. 253 p.

25. TATEO, A.; VALLE, E.; PADALINO, B.; CENTODUCATI, P.; BERGERO D. Change in some physiologic variables induced by Italian Traditional Conditioning in Standardbred Yearling. Journal Equine Veterinary Science, v. 28, n. 12, p. 743-750, 2008.

26. THOMASSIAN, A. Medicina esportiva equina. Da inspeção ao computador: Parte II. 2011. Disponível em: http://www. spmv.org.br/conpavet2004/.../Armen\%20Tomassian-II.doc. Acesso em: 09 fev. 2011.

27.HODGSON, D. R.; ROSE, R. J. Hematology and biochemistry.
In: HODGSON, D. R.; ROSE, R. J. The athletic horse: principle and practice of equine sports medicine. Philadelphia: W.B. Saunders, 1994. p. 63-78.

28.FALASCHINI, A.; TROMBETTA, M. F. Modifications induced by training and diet in some exercise-related blood parameters in young trotters. Journal of Equine Veterinary Science, v. 21, n. 12, p. 601-604, 2001.

29.SANTOS, V. P. Variações hemato-bioquímicas em equinos de salto submetidos a diferentes tipos de protocolos de exercício. 2006. 94 p. Dissertação (Mestrado em Ciências Veterinárias) - Faculdade de Medicina Veterinária e Zootecnia, Universidade Federal do Rio Grande do Sul, Rio Grande do Sul, 2006.

30.ART, T.; LEKEUX, P. Exercise-induced physiological adjustments to stressful conditions in sport horses. Livestock Production Science, v. 92, n. 2, p. 101-111, 2005.

31. MIRIAN, M. Padronização de teste incremental de esforço máximo a campo para cavalos que pratiquem "hipismo clássico". 2008. 72 f. Dissertação (Mestrado em Clínica Veterinária) - Faculdade de Medicina Veterinária e Zootecnia, Universidade de São Paulo, São Paulo, 2008 